

\section{André Bazin y Farrebique}

En diciembre de 2018 se publicaron en Francia los Escritos completos de André Bazin. Bazin es seguramente el crítico de cine cuyos escritos tienen mayor influencia en la historia del cine, via los integrantes de la Nouvelle Vague, a fines de los 50 y en los sesenta (Bazin falleció en 1958, a los 40 años) y, desde entonces, gracias al libro Qué es el cine, que reúne varios de sus textos. La primera edición de Qué es el cine se hizo entre 1958 y 1962, en cuatro tomos. Bazin preparó y escribió el prólogo del primero, y esbozó el orden y la selección del segundo y del tercero. El cuarto tomo estuvo dedicado al Neorrealismo, pero la selección de los textos no fue ni siquiera esbozada por Bazin.

En 1975 el Editor seleccionó, entre los textos de los cuatro tomos algunos de los escritos de Bazin y los publicó en un solo tomo. Son esos textos lo que, traducidos al español, fueron leídos en la Argentina. El responsable de la edición de los Escritos completos de Bazin, Hervé Joubert-Laurencin aclara que el lector de Qué es el cine solo conoce el diez por ciento de lo que Bazin publicó, lo cual es cierto, pero quizá el hecho de ser el «super especialista» en Bazin, le hace exagerar un poco nuestra ignorancia.

Es cierto que los Escritos Completos incluyen los 2.681 textos de Bazin publicados, además de las modificaciones que el propio Bazin introdujera en algunos de los que fueron incluidos en Qué es el cine. Después de Qué es el cine aparecieron otros libros reuniendo algunos de los textos de Bazin que ya habían sido publicados: «El cine de la crueldad, de Buñuel a Hiichcock»; «El cine de la Ocupación y de la Resistencia» editados por François Truffaut, y «El cine francés de la Liberación a la Nueva Ola» compilado por Jean Narboni. Joubert-Laurencin, parafraseando a Resnais, nos dice: «no sabes nada de Bazin» ante lo cual se tiene la tentación de contestar: «no es cierto, conozco sus textos centrales, como Evolución del lenguaje cinematográfico o Montaje prohibido, de modo que algo de Bazin conozco». 